EXTENDED REPORT

\title{
Sustained durability and tolerability of etanercept in ankylosing spondylitis for 96 weeks
}

\author{
J C Davis, D M van der Heijde, J Braun, M Dougados, J Cush, D Clegg, R D Inman, \\ A Kivitz, L Zhou, A Solinger, W Tsuji
}

See end of article for authors' affiliations

.....................

Correspondence to: Assistant

Professor J C Davis, University of California San Francisco, 533

Parnassus Ave Rm U 383 Box 0633, San Francisco, California, USA; idavis@ medicine.ucsf.edu

Accepted 3 April 2005 Published Online First 26 May 2005

\begin{abstract}
Objective: To evaluate the continued safety and durability of clinical response in patients with ankylosing spondylitis receiving etanercept.

Methods: 277 patients who had participated in a previous randomised, double blind, placebo controlled 24 week trial were eligible to continue in this open label extension study. All patients who enrolled in the open label extension ( $n=257$ ) received subcutaneous etanercept $25 \mathrm{mg}$ twice weekly for up to 72 weeks, for a combined 96 weeks of cumulative trial and open label experience. For the patients who had received etanercept for 24 weeks in the double blind trial, this represented almost 2 years of continuous etanercept treatment.

Results: Patients continuing etanercept treatment had a sustained response for almost 2 years, with 74\% achieving an ASsessments in Ankylosing Spondylitis 20\% (ASAS 20) response after 96 weeks of etanercept treatment. Patients who had received placebo in the preceding double blind trial had similar responses, with $70 \%$ of patients attaining an ASAS 20 response after 24 weeks of etanercept treatment and $78 \%$ achieving an ASAS 20 response after 72 weeks. Improved spinal mobility was seen in both groups. Etanercept was well tolerated in patients treated for up to 96 weeks.

Conclusion: The subcutaneous administration of twice weekly doses of etanercept provided sustained durability of response in the improvement of signs and symptoms of ankylosing spondylitis for nearly 2 years.
\end{abstract}

A nkylosing spondylitis (AS) is an inflammatory disease primarily affecting the spine but also the peripheral joints. In a subset of patients the disease is progressive and results in irreversible deformities, disability, and loss of function, which occurs within the first 10 years of disease onset. ${ }^{1}$ Treatment with etanercept has resulted in a significant improvement of disease activity as measured by the ASsessment in Ankylosing Spondylitis (ASAS) response criteria, Bath Ankylosing Spondylitis Disease Activity Index (BASDAI), and Bath Ankylosing Spondylitis Function Index (BASFI). ${ }^{2-7}$

We recently reported results from a randomised clinical trial (RCT), which examined the safety and efficacy of etanercept in patients with AS. At week 12,59\% of patients receiving etanercept had achieved an ASAS 20 response, compared with $28 \%$ of patients receiving placebo. ${ }^{2}$ Spinal mobility also improved by week 12 , with continued improvement seen through 24 weeks.

A follow up open label study examined extended courses of etanercept in the same group of patients with AS, with the aim of examining the tolerability and durability of response associated with longer courses of etanercept. Here, we report the results of 96 weeks' continuous etanercept treatment.

\section{PATIENTS AND METHODS \\ Patients}

This was a multicentre, open label extension study in patients from a previous 24 week, double blind RCT of etanercept in AS. Two hundred and fifty seven of the original 277 randomised patients began the open label extension phase (fig 1). The study was conducted at 28 sites in America, Canada, the Netherlands, Germany, and France. All patients gave informed consent before screening and enrolment in the preceding clinical trial.
At RCT enrolment, patients had active AS and fulfilled the modified New York criteria. Detailed information on the inclusion and exclusion criteria for the RCT have been presented elsewhere. ${ }^{2}$ In this extension study, patients were allowed to continue to take hydroxychloroquine, sulfasalazine, or methotrexate and/or to change the doses at the discretion of the principal investigator at each site.

All patients who completed the RCT were eligible for inclusion in this extension study. Additionally, patients from the RCT who had dropped out at or after 12 weeks because of lack of efficacy were eligible to enrol in the extension study, provided that the patient had returned for all the required follow up visits. Patients who had discontinued because of adverse events were eligible to enrol provided that the event(s) had resolved and that the clinical investigator still considered the patient a candidate for etanercept treatment.

\section{Study design and drug}

Previously, patients received either subcutaneous (SC) etanercept $25 \mathrm{mg}(\mathrm{n}=138)$ or placebo $(\mathrm{n}=139)$ twice weekly2; in this extension study, all patients received SC etanercept $25 \mathrm{mg}$ twice weekly for up to 72 weeks (fig l). For patients who had received etanercept for 24 weeks in the RCT, this represented almost 2 years of continuous etanercept treatment. The study drug was supplied as a sterile lyophilised powder containing $25 \mathrm{mg}$ etanercept (Enbrel; Immunex, subsidiary of Amgen) for reconstitution and self administered SC injection.

Abbreviations: AS, ankylosing spondylitis; ASAS, ASsessment in Ankylosing Spondylitis; BASDAl, Bath Ankylosing Spondylitis Disease Activity Index; BASFI, Bath Ankylosing Spondylitis Function Index; CRP, $C$ reactive protein; $P P D$, purified protein derivative; $R C T$, randomised clinical trial; SC, subcutaneous 


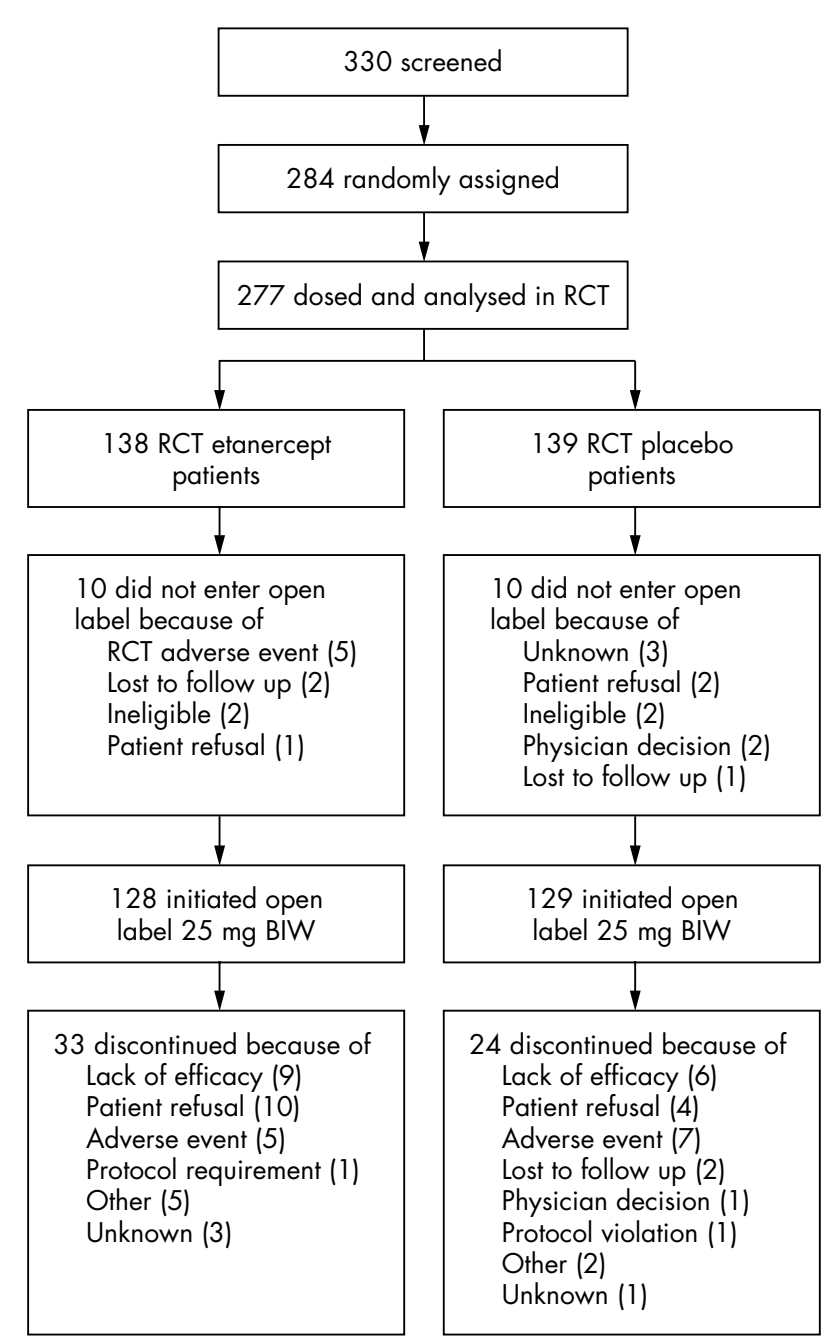

Figure 1 Patient disposition in an open label trial examining sustained durability and tolerability of etanercept in patients with AS. BIW, twice weekly.

\section{Efficacy}

The primary outcome of the preceding RCT was a comparison between the proportion of patients attaining an ASAS 20 response at 12 weeks among patients receiving etanercept and patients receiving placebo. To qualify as an ASAS 20 responder, a patient had to show an improvement of $20 \%$, equating to a minimum improvement of 10 units on a $100 \mathrm{~mm}$ visual analogue scale in at least three of four measures: patient's global assessment; pain; physical function; and inflammation, with no deterioration (defined as a $20 \%$ worsening and absolute change of at least 10 units) in the fourth criterion. ${ }^{8}$ Physical function was measured by the average of the 10 BASFI questions ${ }^{9}$ (range $0=$ easy to perform tasks to $100=$ impossible to perform tasks) and inflammation was represented by the average of the final two questions on the BASDAI assessing severity and duration of morning stiffness ${ }^{10}$ (range $0=$ none to $100=$ very severe).

The durability of response in those patients continuing etanercept from the RCT, as assessed by the proportion of ASAS 20 responders at the end of 72 weeks of open label treatment, was determined. Secondary outcome measures included achievement of the ASAS 50 (50\% and 20 units improvement in the four domains for ASAS 20 criteria, without worsening in the remaining domain) and ASAS 70 (70\% improvement and 30 units in the same four domains, without worsening in the remaining domain). Other outcome measures included the effect of etanercept treatment on nocturnal and total back pain, measurements of spinal mobility (chest expansion, modified Schober's index, and occiput to wall measurements), peripheral joint counts, acute phase reactants, and assessor's global assessment.

We also incorporated the two alternative definitions of the ASAS criteria, based on those set forward by the ASAS international working group, ASAS for Disease Controlling Anti-Rheumatic Therapies: ASAS 40 response and ASAS 5/ 6. ${ }^{11}$

The ASAS 40 response requires a $40 \%$ improvement relative to baseline plus absolute improvement of at least 20 units in any three of four of the ASAS criteria listed above, with no worsening in the remaining criterion.

Our modification of the ASAS 5/6 required a $20 \%$ improvement in five of six criteria-the four criteria of the ASAS response, a measure of spinal mobility, and an acute phase reactant-with no worsening in the remaining criterion. In addition, a 20\% improvement in patient's global assessment; pain; physical function; and/or inflammation was required to equate to an absolute improvement of at least 10 units. This definition is slightly more restrictive than the ASAS 5/6 proposed by Brandt et $a l^{11}$ and is likely to yield a slightly smaller proportion of responders than would have been seen with the original definition. The measures of spinal mobility and acute phase reactant prespecified in the statistical analysis plan were chest expansion and $\mathrm{C}$ reactive protein (CRP), respectively. Brandt et al used lumbar lateral flexion as the measure of spinal mobility. ${ }^{11}$

\section{Safety evaluation}

All patients who received at least one dose of the study drug in the double blind or open label periods were evaluated for safety. The following variables were assessed: results of a physical examination, vital signs, haematology and chemistry profiles, urine analysis, antibodies against etanercept, premature discontinuation, adverse events, serious adverse events, and deaths on study. Adverse events and abnormal laboratory values were graded on a scale derived from the National Cancer Institute Common Toxicity Criteria (common terminology criteria for adverse events available online at http://ctep.cancer.gov, accessed 18 May 2005). Serious adverse events were defined as any events that resulted in death, a life threatening adverse experience, inpatient hospitalisation or prolongation of existing hospitalisation, a persistent or major disability/incapacity, or a congenital anomaly/birth defect.

\section{Statistical analysis}

The percentage of responders as determined by the ASAS response criteria $^{8}$ was determined over time by original treatment group. Efficacy analyses are reported without statistical inference between treatment groups. For both groups of patients, measurements from the baseline visit of the RCT were used as baseline values. Data were combined with the results of the preceding RCT to assess the durability of the ASAS response rates. Efficacy summary tables include all subjects with data available at each given time point.

\section{RESULTS}

\section{Patients}

Of the 277 patients who were dosed and analysed in the RCT, 257 patients started the extension study (fig 1). Ten patients in each RCT group did not enrol in the open label trial. Twelve patients receiving etanercept had discontinued during the RCT. Of these, three patients re-enrolled in the open label trial: two patients who had discontinued at or after 12 weeks owing to a lack of efficacy and one patient who had discontinued because of an adverse event. One patient in 

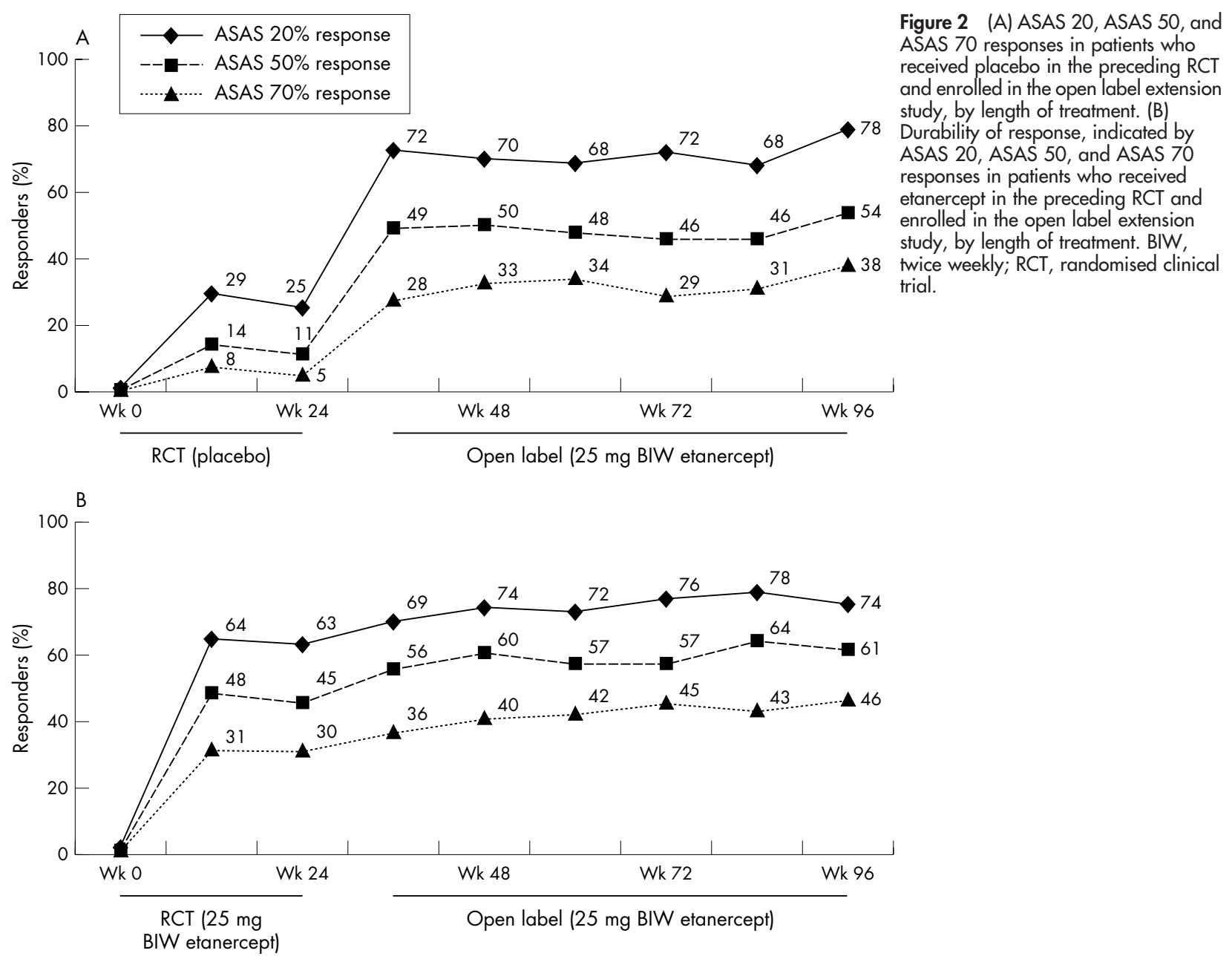

Table 1 Spinal mobility measures after extended etanercept exposure*

\begin{tabular}{|c|c|c|}
\hline & \multicolumn{2}{|c|}{$\mathrm{RCT}$ trial arm } \\
\hline & Etanercept & Placebo \\
\hline \multicolumn{3}{|l|}{ Occiput to wall measurement } \\
\hline RCT baseline & $\begin{array}{l}5.4(0.5) \\
(n=128)\end{array}$ & $\begin{array}{l}5.0(0.6) \\
(n=129)\end{array}$ \\
\hline Week 96 (72 weeks of open label) & $\begin{array}{l}4.0(0.6) \dagger \\
(n=95)\end{array}$ & $\begin{array}{l}4.6(0.7) \ddagger \\
(n=105)\end{array}$ \\
\hline Improvement & $1.5(0.3)$ & $0.3(0.4)$ \\
\hline Median improvement & 0 & 0 \\
\hline \multicolumn{3}{|l|}{ Chest expansion } \\
\hline RCT baseline & $\begin{array}{l}3.4(0.2) \\
(n=128)\end{array}$ & $\begin{array}{l}3.2(0.2) \\
(n=129)\end{array}$ \\
\hline Week 96 (72 weeks of open label) & $\begin{array}{l}4.0(0.2) \dagger \\
(n=95)\end{array}$ & $\begin{array}{l}3.5(0.2) \neq \\
(n=105)\end{array}$ \\
\hline Improvement & $0.7(0.2)$ & $0.2(0.2)$ \\
\hline Median improvement (range) & 0.5 & 0 \\
\hline \multicolumn{3}{|l|}{ Modified Schober's index } \\
\hline RCT baseline & $\begin{array}{l}3.1(0.2) \\
(n=128)\end{array}$ & $\begin{array}{l}3.0(0.1) \\
(n=129)\end{array}$ \\
\hline Week 96 (72 weeks of open label) & $\begin{array}{l}3.5(0.2) \dagger \\
(\mathrm{n}=95)\end{array}$ & $\begin{array}{l}3.2(0.1) \ddagger \\
(n=105)\end{array}$ \\
\hline Improvement & $0.5(0.1)$ & $0.2(0.1)$ \\
\hline Median improvement & 0.5 & 0.3 \\
\hline
\end{tabular}

*Data presented are mean (SE) unless otherwise noted; total of 96 weeks of etanercept: 24 weeks in RCT and 72 weeks of open label treatment; łtotal of 72 weeks of etanercept: 24 weeks of placebo in RCT and 72 weeks of etanercept open label. the etanercept group who had completed the double blind trial declined to enrol in the open label trial (patient refusal). Nineteen patients receiving placebo had discontinued during the RCT. Of these, eight patients who had discontinued because of lack of efficacy enrolled in the open label trial, as did one patient who had discontinued because of an adverse event.

Baseline demographic characteristics of the group who enrolled in the open label extension were therefore very similar to those of the RCT, with a predominantly male (75\%) and white (93\%) population. The mean age of the group was 41.6 years (range $18-70$ years), with a mean disease duration of 10.7 years (range 0.5-35.8). About one third $(31.5 \%$ ) of patients were taking concomitant disease modifying antirheumatic drug treatment, including sulfasalazine $(21.8 \%)$, methotrexate (11.3\%), and hydroxychloroquine (1.6\%). At baseline, the mean (SD) patient global assessment was 63.3 (17.6) and the mean (SD) BASFI was 54.0 (20.6).

One hundred and twenty eight of the patients who enrolled were from the etanercept arm of the preceding trial; the other 129 began etanercept at week 0 of the open label extension study. Two hundred and nine patients received at least 72 weeks of etanercept treatment (104 patients continuing etanercept from the RCT and 105 patients starting etanercept in the open label extension), and 95 received a full 96 weeks.

Sixty seven patients receiving etanercept discontinued (fig 1). This included 10 patients who received etanercept in the RCT but did not enrol in the open label extension. Figure 1 lists the reasons for discontinuation. 
Table 2 Outcomes after extended etanercept exposure*

\begin{tabular}{|c|c|c|c|c|}
\hline & \multicolumn{4}{|l|}{ RCT trial arm } \\
\hline & \multicolumn{2}{|l|}{ Etanercept } & \multicolumn{2}{|l|}{ Placebo } \\
\hline & $\begin{array}{l}\text { RCT Baseline } \\
\text { (n = 128) }\end{array}$ & $\begin{array}{l}\text { Week } 96 \text { of } \\
\text { etanercept† } \\
(n=95)\end{array}$ & $\begin{array}{l}\text { RCT Baseline } \\
\text { (n = 129) }\end{array}$ & $\begin{array}{l}\text { Week } 72 \text { of } \\
\text { etanercept } \\
(n=105)\end{array}$ \\
\hline \multicolumn{5}{|l|}{ ASAS component } \\
\hline Patient's global assessment $(0-100)$ & $63.2(1.5)$ & $26.6(2.6)$ & $63.3(1.6)$ & $28.4(2.3)$ \\
\hline Back pain $(0-100)$ & $61.7(1.8)$ & $24.3(2.6)$ & $63.7(1.8)$ & $27.5(2.6)$ \\
\hline BASFI $(0-100)$ & $51.1(1.8)$ & $25.4(2.4)$ & $56.8(1.8)$ & $32.3(2.5)$ \\
\hline Inflammation§ (0-100) & $60.9(1.9)$ & $22.8(2.6)$ & $65.3(1.8)$ & $28.0(2.4)$ \\
\hline$C R P$ & $1.8(0.2)$ & $0.5(0.1)$ & $2.0(0.2)$ & $0.7(0.1)$ \\
\hline
\end{tabular}

\section{Durability of response}

Patients who had received placebo in the preceding RCT switched to etanercept $25 \mathrm{mg}$ twice weekly at the beginning of the open label period. Response in these patients was rapid and sustained. After receiving 24 weeks of etanercept treatment in the open label period, $70 \%$ of these patients had achieved an ASAS 20 response, compared with 57\% of etanercept patients who had achieved an ASAS 20 response at week 24 of the RCT. ${ }^{2}$ Improvements were seen in all levels of ASAS response in those who entered the open label extension study (fig 2). All mean measures of spinal mobility, including chest expansion, occiput to wall measurement, and modified Schober's index, also improved in this group by the end of 72 weeks of etanercept treatment (table 1).

Patients who had received etanercept in the preceding RCT and enrolled in the open label extension study showed continued and improved ASAS response for up to 2 years of treatment with etanercept (fig 2). At week 24 of the RCT, 57\% of etanercept patients had achieved an ASAS 20 response $^{2}$; after an additional 72 weeks of open label etanercept (week 96, fig 2), 74\% (70/95) of patients had achieved an ASAS 20 response. After 96 weeks of etanercept treatment, almost half (46\%) of these patients had attained an ASAS 70 response. All three mean and two of three median measures of spinal
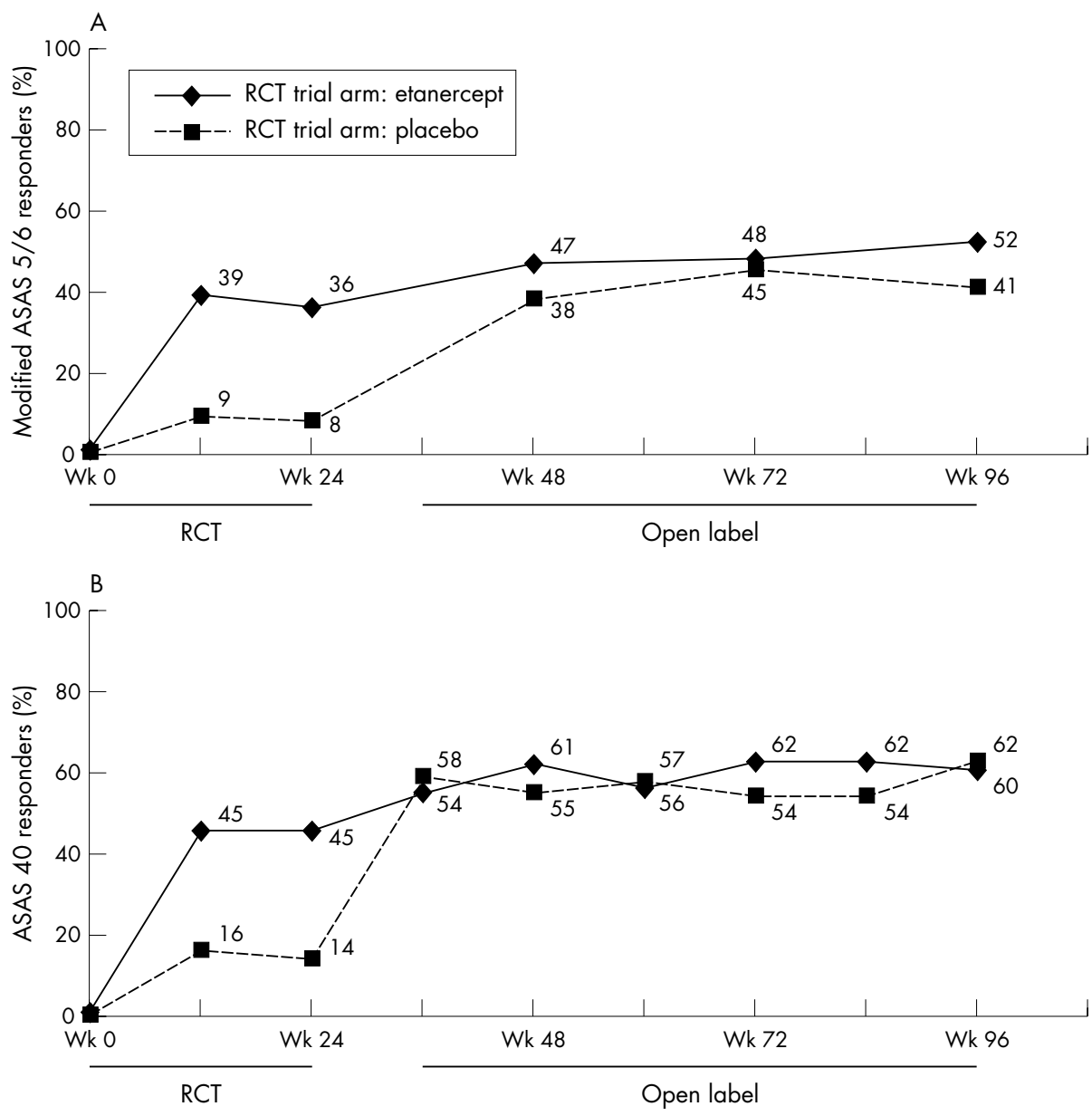

Figure 3 (A) Percentage of patients who attained the modified ASAS $5 / 6$ (20\% improvement in five of six criteria-patient's global assessment, pain, physical function, inflammation, a measure of spinal mobility, and an acute phase reactant-with no worsening in the remaining criterion. In addition, improvement in patient's global assessment, pain, physical function, and/or inflammation by at least 10 units). (B) Percentage of patients who attained ASAS 40 (40\% improvement relative to baseline plus absolute improvement of at least 20 units in any three of four of patient's global assessment, pain, physical function, and/or inflammation, with no worsening in the remaining criterion). 


\begin{tabular}{|ll|}
\hline $\begin{array}{l}\text { Table } 3 \text { Adverse events and infections of any } \\
\text { severity occurring in } \geqslant 5 \% \text { of patients }\end{array}$ \\
\hline & $\begin{array}{l}\text { Open label } \\
\text { experience }(\mathbf{n}=257)\end{array}$ \\
Nodverse event/infection & $53(21)$ \\
\hline Injection site reaction & $39(15)$ \\
Headache & $33(13)$ \\
Injection site bruising & $32(12)$ \\
Diarrhoea & $30(12)$ \\
Abdominal pain & $27(11)$ \\
Accidental injury & $28(11)$ \\
Rash & $20(8)$ \\
Pain (body as a whole) & $19(7)$ \\
Asthenia & $19(7)$ \\
Rhinitis & $19(7)$ \\
Conjunctivitis & $18(7)$ \\
Depression & $18(7)$ \\
Hypertension & $17(7)$ \\
Nausea & $17(6)$ \\
Uveitis & $14(5)$ \\
Arthralgia & $12(5)$ \\
Dizziness & \\
\hline & \\
\hline
\end{tabular}

mobility in patients who had received etanercept in the RCT showed persistent improvement from baseline (table 1). In both these patients and patients who had received placebo in the RCT, the subgroup of patients with limited spinal mobility (defined as baseline occiput to wall $\neq 0$; baseline chest expansion score $<2.5$; or baseline Schober's index $<5$ ) showed positive improvements in all mean and all median measures of spinal mobility (data not shown).

Additional outcomes included the individual components of the ASAS response criteria and CRP (table 2). The group of patients who had received placebo in the RCT improved on all measures. The group of patients who had received etanercept in the preceding RCT demonstrated sustained benefit and, in some cases, continued improvement. In a more stringent definition of response, both groups of patients experienced disease improvement as measured by the ASAS 40 and modified ASAS 5/6 response criteria (fig 3).

\section{Safety}

Most adverse events reported were of mild or moderate intensity; table 3 lists those that occurred in $\geqslant 5 \%$ of patients. Two events occurred in two patients during the open label extension that were considered to be life threatening: an idiopathic third degree heart block and a pulmonary embolus, both of which the investigators considered unrelated to etanercept.

Six patients withdrew from the open label extension because of non-infectious, non-serious adverse events (fig 1), including one patient for an injection site reaction; one patient with dizziness, shortness of breath, and an increased heart rate; one patient with dermatitis and urticaria; two patients with rashes; and one patient with liver steatosis. Seventeen patients experienced serious adverse events, but only four patients discontinued as a result of those events, including one patient who had a flare of Crohn's disease, one patient with a narcotic addiction, one patient with asthmatic bronchitis, and one patient who had worsening depression. All of these events, however, were identified as unrelated to etanercept by the investigators.

Twenty one per cent of patients had injection site reactions during the open label period; only one patient discontinued from the open label extension because of this reaction. The $21 \%$ rate is somewhat lower than the rate seen in the RCT, where $30 \%$ of patients receiving etanercept experienced injection site reactions. ${ }^{2}$ One patient discontinued the RCT because of a fever associated with an injection site reaction.
No deaths were reported in either the RCT or the open label extension.

Some of the extra-articular features of the spondyloarthropathies were also noted as adverse events during the trial; patients with a history of these features were not excluded from the trial. Twenty six patients experienced uveitis or iritis, including 13 patients previously receiving placebo and 13 patients continuing etanercept from the RCT. Four of these patients had reported iritis or uveitis during the RCT and most (14/22) others had a pre-trial history of uveitis or iritis. Colitis was reported in five patients (including one case due to $C$ difficile), ileitis was reported in two patients, and there were single reported cases of psoriasis and balanitis.

Five patients experienced serious infectious episodes after starting etanercept. All of these episodes resolved. One patient discontinued because of a non-serious infectious event (otitis media and a furunculus) and one patient discontinued because of a serious infectious event (a flare of hepatitis B in a foreign-born person).

One patient had a positive purified protein derivative (PPD) test but had none of the signs or symptoms associated with tuberculosis; it was unclear from the case report forms why the PPD test had been performed. Two cases of herpes zoster were reported.

No patients discontinued as a result of laboratory abnormalities. One patient had grade 3 increases in liver enzymes on more than one test date; one patient had grade 3 results from alanine aminotransferase and aspartate aminotransferase determinations on the same date, with all other test dates falling within normal ranges. Two patients had single cases of laboratory abnormalities without any associated adverse events amid consistently normal readings: one patient had a single recorded grade 4 laboratory abnormality, with a platelet count of $3 \times 10^{9} / 1$ on study day 421 despite consistently registered platelet counts $\geqslant 200 \times 10^{9} / 1$ on all other test dates (including study days 337 and 427), and another patient had a single grade 3 increase in liver enzymes on study day 250 (288 U/l) amid consistent test results $\leqslant 40 \mathrm{U} / \mathrm{l}$. The authors believe that these two abnormalities represent spurious laboratory results. A patient with a grade 3 abnormal lymphocyte count before starting the study received only 12 days of etanercept; on study day 63, the patient's lymphocyte count was still grade 3. One additional patient had a grade 4 absolute neutrophil count at baseline that resolved to essentially normal values (toxicity grade 1) by study day 82 .

\section{DISCUSSION}

Treatment of AS has largely consisted of non-steroidal antiinflammatory drugs; most disease modifying antirheumatic drugs have limited efficacy on peripheral symptoms and are not effective in axial manifestations. Etanercept has already been seen to be effective in bringing about a rapid and significant improvement to patients with AS. ${ }^{2-7}$ The ability of etanercept to alter the loss of spinal mobility in these patients is of particular importance.

Patients continued to receive clinical benefit from etanercept in this extension study, including the maintenance of spinal mobility gains made during the RCT. Patients who switched from placebo to etanercept demonstrated improvement in the BASFI and all levels of ASAS response $(20 \%$, $50 \%$, and $70 \%$ ). Overall, the treatment effect in the two groups in the open label extension period was similar, regardless of whether placebo had been started first. Although the gains in spinal mobility in the group of patients who first received placebo may not be as strong as those seen in the original etanercept group, placebo patients as a group nevertheless recovered spinal mobility, as reflected in mean spinal mobility measurements. 
Etanercept continued to be well tolerated in this open label extension study, with no increases in rates of adverse events or serious adverse events over the clinical trial experience. Importantly, none of the most serious safety concerns that have been linked with some tumour necrosis factor inhibitors-tuberculosis, drug-induced lupus, demyelinating diseases such as multiple sclerosis, and lymphomas-were reported in patients receiving etanercept either during the RCT or the subsequent open label extension study. The safety profile was similar to that in the $\mathrm{RCT}^{2}{ }^{2}$ as well as in studies in other disease states such as rheumatoid arthritis, ${ }^{12}{ }^{13}$ psoriatic arthritis, ${ }^{14}$ and psoriasis, ${ }^{15}{ }^{16}$ suggesting that the safety profile of etanercept is similar in the short and long term. In the 24 weeks of the RCT, 11 patients reported uveitis or iritis; after 72 weeks of etanercept in the open label period, 26 patients reported uveitis or iritis (including four of the patients who had reported uveitis/iritis in the RCT). Similarly, five patients reported colitis or ileitis in the 24 week RCT and seven reported colitis or ileitis in the 72 week extension. Although the RCT and this study were not powered to discern efficacy in the prevention of uveitis/iritis or colitis, these results suggest that etanercept does not increase the incidence in 72 weeks over that expected in this population.

One obvious limitation of this study is that the completer's analysis allows for the attrition of patients over time, which can have the effect of enriching the population for responders. However, this analysis has the strength of examining the ability of etanercept to deliver sustained benefit, which here is demonstrated for nearly 2 years. In a patient population with a need for chronic treatment to prevent progressive disability, the ability of a drug to provide sustained benefit coupled with long term tolerability is critically important. Of note, analyses using the last observation carried forward for patients who dropped out yielded proportions of responders similar to those measured by the ASAS 20, ASAS 40, ASAS 50, ASAS 70, and ASAS 5/6.

Taken together, these data demonstrate the continued effectiveness and tolerability of etanercept in patients with AS. Current experience demonstrates nearly 2 years of sustained benefit. We believe that the improvement of spinal mobility is an especially promising effect of etanercept treatment; imaging studies may shed more light on the effect of etanercept on structural damage.

\section{ACKNOWLEDGEMENTS}

We thank Elizabeth HZ Thompson, PhD, for assistance with preparation of the manuscript.

This study was funded by Immunex Corporation, a wholly owned subsidiary of Amgen Inc, and by Wyeth Research.

\section{Authors' affiliations}

J C Davis, Division of Rheumatology, University of California, San

Francisco, San Francisco, USA

D M van der Heijde, Department of Rheumatology, University Hospital Maastricht, Maastricht, The Netherlands
J Braun, Rheumazentrum, Ruhrgebiet, Landgrafenstr, Germany M Dougados, Rhumatologie B, Hopital Cochin, Paris, France J Cush, Arthritis Consultation Center, Presbyterian Hospital of Dallas, Dallas, USA

D Clegg, Division of Rheumatology, University of Utah Health Sciences Center, Salt Lake City, USA

R D Inman, Toronto Western Hospital, Toronto, Ontario, Canada

A Kivitz, Clinical Research, Altoona Center for Clinical Research,

Duncansville, USA

L Zhou, A Solinger, W Tsuji, Development, Amgen, Thousand Oaks, USA

\section{REFERENCES}

1 Braun J, Golder W, Bollow M, Sieper J, van der Heijde D. Imaging and scoring in ankylosing spondylitis. Clin Exp Rheumatol 2002;20:S178-84.

2 Davis JC Jr, van der Heijde D, Braun J, Dougados M, Cush J, Clegg DO, et al. Recombinant human tumor necrosis factor receptor (etanercept) for treating ankylosing spondylitis: a randomized, controlled trial. Arthritis Rheum 2003:48:3230-6

3 Cohen J. Clinical and laboratory improvement in ankylosing spondylitis after treatment with etanercept: a case report. J Clin Rheumatol 2000;6:221-4.

4 Marzo-Ortega H, McGonagle D, O'Connor P, Emery P. Efficacy of etanercept in the treatment of the entheseal pathology in resistant spondylarthropathy: a clinical and magnetic resonance imaging study. Arthritis Rheum 2001;44:2112-17.

5 Gorman JD, Sack KE, Davis JC Jr. Treatment of ankylosing spondylitis by inhibition of tumor necrosis factor alpha. N Engl J Med 2002;346:1349-56.

6 Brandt J, Khariouzov A, Listing J, Haibel H, Sorensen H, Grassnickel L, et al. Six-month results of a double-blind, placebo-controlled trial of etanercept treatment in patients with active ankylosing spondylitis. Arthritis Rheum 2003:48: 1667-75.

7 Calin A, Dijkmans BAC, Emery P, Hakala M, Kalden J, Leirisalo-Repo M, et al. Outcomes of a multicentre randomised clinical trial of etanercept to treat ankylosing spondylitis. Ann Rheum Dis 2004;63:1594-600.

8 Anderson JJ, Baron G, van der Heijde D, Felson DT, Dougados M. Ankylosing spondylitis assessment group preliminary definition of short-term improvement in ankylosing spondylitis. Arthritis Rheum 2001;44:1876-86.

9 Calin A, Garrett S, Whitelock H, Kennedy LG, O'Hea J, Mallorie P, et al. A new approach to defining functional ability in ankylosing spondylitis: the development of the Bath Ankylosing Spondylitis Functional Index. J Rheumatol 1994;21:2281-5.

10 Garrett S, Jenkinson T, Kennedy LG, Whitelock H, Gaisford P, Calin A. A new approach to defining disease status in ankylosing spondylitis: the Bath Ankylosing Spondylitis Disease Activity Index. J Rheumatol 1994;21:2286-91.

11 Brandt J, Listing J, Sieper J, Rudwaleit M, van der Heijde D, Braun J. Development and preselection of criteria for short term improvement after anti-TNF\{alpha\} treatment in ankylosing spondylitis. Ann Rheum Dis 2004;63:1438-44.

12 Moreland L, Schiff M, Baumgartner S, Tindall E, Fleishmann R, Bulpitt K, et al. Etanercept therapy in rheumatoid arthritis: a randomized, controlled trial. Ann Intern Med 1999; 130:478-86.

13 Weinblatt ME, Kremer JM, Bankhurst AD, Bulpitt KJ, Fleischmann RM, Fox RI, et al. A trial of etanercept, a recombinant tumor necrosis factor receptor:Fc fusion protein, in patients with rheumatoid arthritis receiving methotrexate. N Engl J Med 1999;340:253-9.

14 Mease PJ, Goffe BS, Metz J, VanderStoep A, Finck B, Burge DJ. Etanercept in the treatment of psoriatic arthritis and psoriasis: a randomised trial. Lancet 2000;356:385-90.

15 Leonardi CL, Powers JL, Matheson RT, Goffe BS, Zitnik R, Wang A, et al. Etanercept as monotherapy in patients with psoriasis. N Engl J Med 2003;349:2014-22.

16 Gottlieb AB, Matheson RT, Lowe N, Krueger GG, Kang S, Goffe BS, et al. A randomized trial of etanercept as monotherapy for psoriasis. Arch Dermatol 2003;139:1627-32. 